\title{
PERCEPÇÃO DOS ACOMPANHANTES SOBRE DISPOSITIVOS INVASIVOS EM UMA UNIDADE DE TERAPIA INTENSIVA PEDIÁTRICA
}

Maria Juliana de Morais Ferreira ${ }^{1}$, Regina Cláudia Melo Dodt'², Adrielle Maia Lima1 ${ }^{1}$, Daniele Rocha de Farias Marques ${ }^{3}$, Sabrina Magalhães Pedrosa Rocha Pinheiro ${ }^{4}$

\begin{abstract}
: Objetivo: verificar a percepção dos acompanhantes sobre dispositivos invasivos em Unidade de Terapia Intensiva Pediátrica. Metodologia: estudo do tipo descritivo com abordagem qualitativa realizado em Unidade de Terapia Intensiva Pediátrica de um hospital de referência em emergência traumato-ortopédico de Fortaleza, com dezessete acompanhantes, no período de julho a agosto de 2016. Utilizou-se para coleta de dados o formulário, analisados por meio da análise de conteúdo. Resultados: foram organizados em três categorias, intituladas caracterização dos acompanhantes participantes da pesquisa, sentimentos de estar acompanhante: ansiedade e medo, e significação dos dispositivos invasivos para o acompanhante. Conclusão: conclui-se que os acompanhantes que receberam informes sobre os dispositivos invasivos souberam identificar e discorrer sobre sua utilidade de forma parcial ou completa. Aqueles que não obtiveram informações sobre os dispositivos apresentaram sentimentos de medo e ansiedade.
\end{abstract}

Descritores: Assistência Centrada no Paciente, Enfermagem Pediátrica, Unidades de Terapia Intensiva Pediátrica, Família.

\section{PERCEPTION OF THE COMPANIONS ABOUT INVASIVE DEVICES IN A PEDIATRIC INTENSIVE CARE UNIT}

ABSTRACT: Objective: to verify the perception of the companions about invasive devices in Pediatric Intensive Care Unit. Methodology: a descriptive study with a qualitative approach carried out in a Pediatric Intensive Care Unit of a reference hospital in a trauma-orthopedic emergency in Fortaleza, with seventeen caretakers, from July to August 2016. Data collection was used to collect data analyzed through content analysis. Results: were organized in three categories, entitled characterization of accompanying participants of the research, feelings of accompanying: anxiety and fear, and significance of invasive devices for the companion. Conclusion: it was concluded that the companions who received reports on the invasive devices were able to identify and discuss their usefulness partially or completely. Those who did not get information about the devices had feelings of fear and anxiety.

Descriptors: Patient Centered Care, Pediatric Nursing, Pediatric Intensive Care Units, Family.

\section{LA PERCEPCIÓN DE LOS COMPAÑEROS EN LOS DISPOSITIVOS INVASIVOS EN UNIDAD DE CUIDADOS INTENSIVOS PEDIÁTRICOS}

Objetivo: verificar la percepción de los acompañantes sobre dispositivos invasivos en Unidad de Terapia Intensiva Pediátrica. Metodología: estudio del tipo descriptivo con abordaje cualitativo realizado en Unidad de Terapia Intensiva Pediátrica de un hospital de referencia en emergencia traumato-ortopédico de Fortaleza, con diecisiete acompañantes, en el período de julio a agosto de 2016. Se utilizó para la recolección de datos. de acuerdo con el análisis de contenido. Resultados: fueron organizados en tres categorías, tituladas caracterización de los acompañantes participantes de la investigación, sentimientos de estar acompañante: ansiedad y miedo, y significación de los dispositivos invasivos para el acompañante. Conclusión: se concluye que los acompañantes que recibieron informes sobre los dispositivos invasivos supieron identificar y discurrir sobre su utilidad de forma parcial o completa. Aquellos que no obtuvieron información sobre los dispositivos presentaron sentimientos de miedo y ansiedad.

Descriptores: Asistencia Centrada en el Paciente, Enfermería Pediátrica, Unidades de Terapia Intensiva Pediátrica, Familia. 


\section{INTRODUÇÃO}

O Estatuto da Criança e do Adolescente (ECA), no Capítulo I, Art. 12, garante a permanência em tempo integral de um dos pais ou responsável, nos casos de internação de criança ou adolescente, devendo os estabelecimentos de saúde garantir a atenção às necessidades básicas de saúde dos mesmos ${ }^{1}$.

A familia durante o processo de hospitalização encontrase fragilizada no que diz respeito aos seus anseios, precisando de apoio e orientação profissional. Este fato sinaliza o quanto a equipe de enfermagem ainda pode mostrar-se dispersa no que diz respeito a quesitos que ultrapassam a questão física e biológica, devendo, assim, estender seus cuidados para além do ser doente, ao ser que exerce o papel de acompanhante. Afinal, o cuidado é centrado na família.

Levando em consideração a forma abrupta em que a familia é inserida no contexto hospitalar, pode-se imaginar o impacto de ter um filho em uma Unidade de Terapia Intensiva Pediátrica (UTIP). Destaca-se que muitos pais e acompanhantes nunca tiveram contato anterior com o ambiente hospitalar, em especial, o destinado a pacientes críticos, onde há real possibilidade de perda do ente querido, e ainda, o completo desconhecimento sobre os diversos equipamentos destinados às monitorizações e procedimentos invasivos realizados.

Nesse ambiente intensivo, circulam vários profissionais de diversas especialidades, a fim de proporcionar uma assistência de qualidade ao paciente crítico pediátrico, que precisa, muitas vezes, de monitorização, infusão de fármacos, suporte ventilatório e a utilização de diversos aparatos tecnológicos ${ }^{2}$. Deve-se compreender que a presença do acompanhante ultrapassa os quesitos legais, uma vez que se acredita nos benefícios da recuperação do infante quando se tem ao seu lado um familiar próximo, dando suporte não só nos cuidados diretos, mas aos de cunho emocional.

É preciso, desta forma, desenvolver um olhar apurado e consciente que aquele familiar/acompanhante, apesar de ajudar nos cuidados para com a criança e/ou adolescente, fica por vezes confuso e dominado pelo medo, sobretudo no que diz respeito a situações que excedem sua compreensão.

A mãe associa a UTIP a aparelhos de ventilação mecânica, sondas, eletrodos, cateteres. Esses aparelhos e dispositivos são caracterizados como um dos fatores mais traumáticos da hospitalização ${ }^{3}$. O parente presente muitas vezes se encontra fragilizado, tanto pelo agravo do ente querido, como pela escassez de informações ou por esclarecimentos ineficazes, tornando cada procedimento e dispositivo uma agressão de cunho desconhecido. A experiência da intubação é percebida inicialmente pelos acompanhantes como um momento de impacto, em que estes se mostram assustados com o ambiente e os recursos da UTIP ${ }^{4}$.
$\mathrm{Na}$ prática diária, o que presenciamos, por vezes, é o completo desconhecimento dos familiares acerca dos inúmeros dispositivos invasivos, como os acessos venosos centrais, cateteres de hemodiálise, drenos, tubo endotraqueal, ventilador mecânico, entre outros. O cuidado de enfermagem deve ser estendido ao ser acompanhante para que este se sinta acolhido em suas demandas, podendo expressar seus medos e temores. Desta forma, o acompanhante poderá tornar-se, de fato, um potencializador de melhora clínica ao paciente.

Diante do exposto, este artigo objetiva verificar a percepção dos acompanhantes sobre dispositivos invasivos em uma Unidade de Terapia Intensiva Pediátrica.

\section{METODOLOGIA}

Trata-se de um estudo exploratório, descritivo, de abordagem qualitativa. Este estudo foi realizado em uma UTIP de um hospital de referência em emergência traumatoortopédico de Fortaleza.

Para a determinação do número de participantes, utilizouse o critério de saturação dos dados, ou seja, quando os discursos tornaram-se repetitivos e as informações já colhidas apontavam para uma discussão teórica, atendendo ao objetivo do estudo, encerrou-se a coleta.

A metáfora se configura quando se diz que o processo de coleta de dados se saturou teoricamente, ou seja, quando o pesquisador cogita a ocorrência de uma espécie de descarte dos dados mais recentemente coletados, porque não mais contribuem para a elaboração teórica pretendida. Na prática das pesquisas, é comum que o indicador repetição dos dados seja utilizado para inferir esta redundância e decantamento ${ }^{5}$.

Os dados foram obtidos no período de julho a agosto de 2016, utilizando- se a técnica da aplicação de um formulário. A unidade possui sete leitos destinados a crianças de 0 a 17 anos de idade internadas por patologias diversas, sendo as de caráter traumáticos as mais prevalentes. A aplicação dos formulários foi realizada nas instalações da referida unidade, após assinatura do Termo de Consentimento Livre e Esclarecido sendo preservada a privacidade e evitando-se interrupções.

Participaram do estudo dezessete sujeitos, cujo critério de inclusão foi ser acompanhante da criança durante sua internação e concordar em participar da pesquisa após serem orientados acerca dos objetivos e metodologia.

O anonimato dos sujeitos foi respeitado utilizando-se um código alfanumérico - formulário (Al, A2, A3...) para identificálos em seus depoimentos.

O processo de análise foi realizado por meio do método de análise de conteúdo, do tipo temático. Este método segue três fases: pré-análise; exploração do material; e tratamento, 
inferência e interpretação dos resultados obtidos.

A presente pesquisa foi aprovada pelo Comitê de Ética em Pesquisa da instituição de origem do estudo, com parecer no 1.617.117, contemplando a Resolução 466/2012. Todos os participantes foram esclarecidos sobre os objetivos do estudo e as implicações de sua participação, recebendo garantia de anonimato e da possibilidade de desistir do estudo a qualquer momento.

\section{RESULTADOS}

\section{1) Caracterização dos acompanhantes participantes da pesquisa}

Participaram do estudo dezessete acompanhantes de pacientes internados em UTIP nos meses de julho a agosto de 2016. Desse total, 59\% eram do gênero feminino e $41 \%$ do gênero masculino.

A faixa etária preponderante dos acompanhantes neste periodo variou entre 20 e 29 anos, totalizando 47\%, e caracterizava-se por baixa escolaridade, pois $35 \%$ possuiam ensino fundamental completo e $23 \%$ ensino fundamental incompleto.

A maioria das crianças esteve acompanhada predominantemente pela mãe (47\%) e pelo pai (35\%), seguido em menor proporção pelos tios, primos, irmão e amigo.

Durante a captação dos dados, observou-se que não houve uma profissão em destaque apresentada pelos acompanhantes. As profissões encontradas foram: 17\% do lar, $17 \%$ agricultor, $17 \%$ acadêmicos, $12 \%$ auxiliares de serviços gerais, e $7.4 \%$ distribuídos entre outras categorias.

Em relação ao tempo de hospitalização, 47\% estavam internadas a até quatro dias, 52,9\% a mais de quatro dias. Quanto à experiência anterior como acompanhante, 41\% estavam pela primeira vez exercendo esse papel.

Sabe-se que a UTI é caracterizada pelo seu arsenal tecnológico e esse ambiente, para os familiares das crianças internadas, trata-se de um local assustador, que pode gerar inúmeros conflitos, e por estas características exige dos profissionais preparo técnico e científico ${ }^{6}$

Quando questionados sobre o recebimento de orientações em relação aos dispositivos invasivos: 65\% dos acompanhantes relataram não terem recebido nenhum tipo de informação. Dos 35\% que relataram ter recebido, foram destacados os seguintes profissionais como os responsáveis pelo repasse de informações: três enfermeiras, um médico, um técnico de enfermagem, um psicólogo e um profissional não identificado.

Os que responderam de forma completa demonstravam melhor entendimento sobre as funções de cada dispositivo e mostraram-se mais compreensivos sobre a necessidade da internação em UTI: "Sonda para que ele possa se alimentar. Tubo de ventilação. Cateter venoso central para as medicações. E só." (A8); "Sim. Só agulha pra soro e medicação." (A2)

Determinados acompanhantes, todavia descreveram corretamente a função de alguns dispositivos invasivos instalados em seu paciente, porém, não abarcaram em seu discurso o total de dispositivos: "Disse que sim. Sonda vesical de demora porque não conseguia urinar. E agulha de soro porque não está se alimentando devidos os vômitos." (Al); "Negócio no nariz para se alimentar. Do pescoço para respirar. O resto eu não sei."(A5); "BIC é para o soro. Pressão. Cateter na coxa é para a medicação." (A7); "Coisas pra ver a pressão. Verificar o pulmão. Bomba pra oxigenar e sedar." (A10).

\section{2) Sentimentos de estar acompanhante: ansiedade e medo}

Ao serem questionados sobre como se sentiam ao ver seu familiar conectado a dispositivos invasivos, as repercussões foram diversas, mas todas relacionadas com aspectos subjetivos.

Alguns aspectos subjetivos foram bem marcantes durante o estudo, como o relato de sentirem-se nervosos ao ver seu ente querido com todos aqueles dispositivos. O choro, por vezes, surgiu como resposta a alguns questionamentos, assim como aspectos mais particulares como podemos observar: "Muita vontade de chorar." (A3); "Horrivel. Pior sensação do mundo." (A6); "Agonia. Um aperto no coração" (Al0); “Uma coisa ruim. Vê-lo brincando e agora ver ele assim. Sensação estranha" (Al4).

\section{3) Significações dos dispositivos invasivos para o acompanhante}

Estar em uma UTIP, exercendo o papel de acompanhante, acarreta inúmeras significações para esse indivíduo, desde a própria hospitalização da criança/adolescente, o ambiente hostil, rotinas rígidas e desconhecidas, além da criticidade do quadro clínico do paciente, ou seja, a possibilidade de morte real.

Apesar do impacto e do medo relacionados aos dispositivos, os acompanhantes relataram que esses mecanismos são responsáveis pela manutenção da vida e a melhora clínica do infante: "Representa a saúde". (Al); "Importante para recuperação dela. É o que está deixando ela viver né." (A3); “Representa uma ajuda". (A6); "Salvação da vida” (Al7)

Dos dezessete acompanhantes participantes, somente um se associou a internação em UTI à possibilidade de morte em seu discurso. Esse fato mostra o quanto o ambiente hospitalar, em especial a UTIP, pode ser assustador e desconhecido para aqueles que estão desempenhando o 
papel de cuidador de seu familiar: "Representa a morte" (Al2)

Nas demais falas, pode-se observar uma tentativa de compreender melhor o que significava o dispositivo para o tratamento, como funcionam e como estariam contribuindo para a recuperação de seu familiar: "Representa que está mantendo a vida dele."(A7); "Representa uma ajuda pra ele. Sem eles, ele não estaria vivo."(A8); “Representa ele está no estado que o corpo dele por si só não pode manter ele vivo." (A9): "Sei que é para o bem do meu filho. É para ele melhorar. Se não fosse os aparelhos só Deus sabe o que tinha acontecido." (AlO)

\section{DISCUSSÃO}

Os dados desse estudo corroboram para o fato de que, quanto menor a escolaridade, mais difícil a compreensão sobre o que são e para que servem os dispositivos invasivos. Observa-se em 35\% da amostra o nivel de escolaridade baixo, ou seja, ensino fundamental completo, portanto, exige-se da equipe de enfermagem, uma vez que esta se encontra diretamente ligada à execução dos procedimentos, uma atenção mais integral, oferecendo orientações que estejam em concordância com o nível de entendimento do acompanhante.

Observa-se que mais da metade dos acompanhantes não receberam as devidas orientações e o quanto este fato pode potencializar seus sentimentos de fragilidade e impotência. O desconhecido gera medo e sofrimento pelo fato de não saber ao certo o que ocorre com seu familiar, ou mesmo o significado de todos aqueles dispositivos implantados.

A hospitalização de uma criança pode ser considerada uma fatalidade na vida de uma família. Além do sofrimento causado pela própria doença, a hospitalização em si já é considerada fatigante e causadora de alterações na maioria dos aspectos da vida familiar ${ }^{7}$

É nesse ambiente frio, cercado de tecnologia e de cuidados intensivos que a família se insere, na maioria das vezes, com pouco conhecimento sobre os equipamentos utilizados, sobre os cuidados prestados ao seu ente, e até mesmo sobre a condição de saúde da criança² .

Acredita-se que umas das formas de minimizar esses sentimentos que emergem diante destas situações hostis, seja um esclarecimento prévio sobre o que seria a UTI e qual a sua finalidade, levando em consideração as necessidades e demandas particulares do ser acompanhante. Dentre as queixas principais apresentadas pelos acompanhantes, destaca-se a falta de informação acerca da terapêutica a ser realizada na criança. Relatam que gostariam de ser informadas acerca do tratamento, pois muitas crianças se internam apenas devido à intervenções medicamentosa ${ }^{8}$.
Outro aspecto muito presente no ambiente hospitalar é a ansiedade. Ansiedade é definida como sentimento de desconforto ou temor, acompanhado por resposta autonômica (a fonte é frequentemente não específica ou desconhecida para o indivíduo); sentimento de apreensão causada pela antecipação de perigo. É um sinal de alerta que chama a atenção para um perigo iminente e permite ao individuo tomar medidas para lidar com a ameaça ${ }^{9}$

A falta de comunicação entre profissionais e familiares, em algumas situações, fica comprometida devido às inúmeras atribuições que a equipe de enfermagem tem de exercer. O que leva a falta de uma escuta qualificada, comprometendo assim não só a relação profissional-família, como inviabilizando um atendimento humanizado.

Desta forma, para ajudar a família a enfrentar a experiência de ter uma criança hospitalizada em uma unidade pediátrica, o enfermeiro deve preocupar-se com questões que ultrapassam os aspectos físicos da unidade, o conhecimento da patologia e o tratamento da criança; assim, torna-se imprescindivel que este conheça a família para propor as intervenções ${ }^{10}$.

Levando em consideração os discursos, evidenciase a importância de incluir e compreender o familiar acompanhante. Este possui dúvidas e receios que permeiam o processo de hospitalização e que devem ser acolhidos pela equipe de enfermagem. Os aspectos técnicos possuem relevância neste contexto, todavia os aspectos subjetivos, quando não acolhidos, podem repercutir negativamente no processo de cuidado.

Diante desta situação específica, há a exigência de utilização de diversos dispositivos invasivos para manutenção da vida, o acompanhante pode associar a gravidade do quadro à quantidade de dispositivos implantados no paciente. Além disso, o acompanhante já não reconhece naquela imagem corporal o seu ente querido, o que reforça sentimentos de medo pela possibilidade da finitude.

Verificamos, assim, que o acompanhante é acometido por uma sucessão de acontecimentos, desde o agravo que ocasionou a internação de seu familiar até sua internação de fato e, com isso, uma infinitude de procedimentos que fogem a sua compreensão. Além disso, somam-se sentimentos de impotência, medo e temor diante da morte. A equipe de enfermagem, como aquela que está na linha de frente, pode e deve acolher este indivíduo, uma vez que ele é um aliado no processo de recuperação do paciente.

O presente estudo tem limitação quanto aos resultados, tendo em vista ter sido realizado em apenas um ambiente hospitalar, representando um número restrito de participantes, porém, o suficiente para obtenção de respostas ao objetivo proposto. 


\section{CONCLUSÕES}

A hospitalização de uma criança em UTI pediátrica traz repercussões para o seu acompanhante, sendo que o nível de escolaridade repercute diretamente no entendimento sobre o que são os dispositivos invasivos assim os acompanhantes que receberam informes sobre os dispositivos invasivos souberam identificar e discorrer sobre sua utilidade de forma parcial ou completa. Aqueles que não obtiveram informações sobre os dispositivos apresentaram sentimentos de medo e ansiedade.

Nesse contexto, a equipe de enfermagem é o contato mais duradouro durante todo o processo de cuidado, oferecendo atendimento humanizado e holístico. As inúmeras atribuições executadas por esses profissionais não devem ser um fator dificultador para o fornecimento de informações e esclarecimentos referentes ao ambiente de UTI, nem sobre os dispositivos implantados.
O processo de adoecimento proporciona sentimentos de medo e ansiedade, e uma abordagem humanizada e centrada na necessidade de cada acompanhante, quando levado em consideração seu nível de entendimento, traz respostas positivas para o relacionamento profissional-acompanhante, repercutindo no tratamento da criança.

Outras estratégias podem ser utilizadas para amenizar o impacto sofrido por estar como acompanhante, utilizando como recursos os vídeos interativos e panfletos ilustrativos. Além disso, pode-se fornecer ao ser acompanhante um espaço de escuta, onde este se sinta acolhido e possa esclarecer suas dúvidas.

\section{REFERÊNCIAS}

1. Estatuto da Criança e do Adolescente (BR). Lei no 8.069 de 13 de julho de 1990. Dispõe sobre o Estatuto da Criança e do Adolescente e dá outras providências. Brasilia:DF; 1991.

2. Cardoso JMRM, Rodrigues BMR, Pacheco STA, Araújo BBA. Ação intencional do familiar junto da criança em centro de terapia intensiva pediátrico. Rev. Enfermagem UERJ. 2013; 21(esp.1): 600-5.

3. Santos LM, Oliveira VM, Santana RCB , Fonseca MCC, Neves ES Santos MCS. Vivências maternas na unidade de terapia intensiva pediátrica. R. pesq.: cuid. fundam. online 2013; 5(1): 3432-42

4. Gequelin J ,Fernandes KF, Oliveira GP ,Dyniewicz AM. Percepção de acompanhantes sobre a criança Intubada em uti pediátrica. Cogitare Enferm. 2014; 19(3): 483-90

5. Denzin, N. K., Lincoln, Y. S. (1994). Handbook of qualitative research. Thousand Oaks: Sage.

6. Reis LS, Silva EF, Waterkemper R, Lorenzini E, Cecchetto FH. Percepção da equipe de enfermagem sobre humanização em unidade de tratamento intensivo neonatal e pediátrica. Rev Gaúcha Enferm. 2013; 34(2):118-124.
7. Rolim, KMC. "Imaginário de Mães Acerca da Hospitalização do Filho na Unidade de Terapia Intensiva Neonatal." Enferm Foco [Internet]. 2016 [cited 2018 Jul 30]; 7.1 (2016): 42-4. Available from: http:// http:// revista.cofen.gov.br/index.php/enfermagem/article/view/664/283

8. Strasburg AC, Pintanel AC, Gomes GC, Mota MS. Cuidado de enfermagem a crianças hospitalizadas: percepção de mães acompanhantes. Rev. enferm. UERJ, Rio de Janeiro, 2011; 19(2):262-7.

9. Faquinello P . Higarashi IH , Sonia Silva Marcon SS. Atendimento humanizado em unidade pediátrica: percepção do acompanhante da criança hospitalizada. Texto Contexto Enferm, Florianópolis, 2007: 16(4): 609-16

10. Herdman TH, Kamitsuru S. Diagnósticos de enfermagem da NANDA: definições e classificação 2015-2017. 10.ed. Porto Alegre: Artmed: 2015 